\title{
Severe Milk-Alkali Syndrome in a Patient with Hypoparathyroidism Associated with 1,25(OH)2D, Hydrochlorothiazide and Anthranoid Laxative Consumption
}

\author{
Lorenzo Morini ${ }^{1}$, Davide Donelli ${ }^{2}$, Rosaria Santi ${ }^{1}$, Chiara Trenti $^{1}$, Giuseppe Battaglino ${ }^{3}$, \\ Francesco lannuzzella ${ }^{3}$, Emanuele Alberto Negri ${ }^{1}$ \\ ${ }^{1}$ Alta Intensità Medica, Department of Internal Medicine, Arcispedale Santa Maria Nuova, Reggio Emilia, Italy \\ ${ }^{2}$ CdLM Medicina e Chirurgia, University of Parma, Parma, Italy \\ ${ }^{3}$ Nephrology and Dialysis, Department of Specialist Medicine, Arcispedale Santa Maria Nuova, Reggio Emilia, Italy
}

\section{Doi: 10.12890/2017_000729 - European Journal of Case Reports in Internal Medicine - @ EFIM 2017}

\begin{abstract}
Received: 04/09/2017
Accepted: $23 / 09 / 2017$
\end{abstract}

Published: 04/10/2017

How to cite this article: Morini L, Donelli D, Santi R, Trenti C, Battaglino G et al. Severe milk-alkali syndrome in a patient with hypoparathyroidsm associated with 1,25(OH)D, hydrochlorothiazide and anthraxanoid laxative consumption. EJCRIM 2017;4: doi:10.12890/2017_000729

Conflicts of Interests: The Authors declare that there are no competing interests.

Acknowledgements: The Authors gratefully acknowledge Ombretta Savazza for her participation, and Fabio Firenzuoli for his contribution.

This article is licensed under a Commons Attribution Non-Commercial 4.0 License

\section{ABSTRACT}

Background: Milk-alkali syndrome is a life-threatening condition defined by the triad of hypercalcaemia, metabolic alkalosis and acute renal failure, and is associated with consumption of calcium and absorbable alkali.

Methods: We report the case of a patient admitted to a step-down unit of a large hospital in Italy.

Results: The patient was a 59-year-old woman with hypoparathyroidism and mild chronic kidney insufficiency, treated for a preceding episode of hypocalcaemia with high doses of calcitriol and calcium carbonate, who was also taking hydrochlorothiazide and unreported herbal anthranoid laxatives. The patient was admitted to hospital with severe hypercalcaemia, severe metabolic alkalosis and acute renal insufficiency. The patient was successfully treated with urgent dialysis, loop diuretics and calcitonin administration.

Conclusions: This case underlines the need for caution when treating patients with impaired calcium metabolism regulation, and suggests that herbal anthranoid laxatives might act as triggers for milk-alkali syndrome.

\section{LEARNING POINTS}

- Patients with hypoparathyroidism are more prone to develop milk-alkali syndrome.

- Patients need careful follow-up and review of their need for calcium supplements.

- Non-prescription and complementary medicines can aggravate hypercalcaemia.

\section{KEYWORDS}

Hypoparathyroidism, hypercalcaemia, alkalosis, renal insufficiency, anthraquinones 


\section{CASE DESCRIPTION}

Hypercalcaemia, metabolic alkalosis and acute renal failure, associated with oral intake of high doses of calcium and absorbable alkali, is known as milk-alkali syndrome. This is a life-threatening condition if not properly diagnosed and treated, whose incidence is rising due to the more frequent therapeutic use of calcium carbonate ${ }^{[1]}$. Here we present the case of a patient with hypoparathyroidism and mild chronic renal insufficiency, who was treated with high doses of calcitriol and calcium carbonate while also taking a hydrochlorothiazide and herbal anthranoid laxatives.

\section{METHODS AND RESULTS}

An obese, 59-year-old woman with mild chronic renal insufficiency, hypothyroidism and hypoparathyroidism secondary to a radical thyroidectomy performed 8 years previously for papillary thyroid cancer, presented after falling at home and complained of weakness, dizziness, unsteadiness, numbness and confusion lasting a week. The patient also had hypertension, and was under oral anticoagulant therapy after aortic valve replacement with a mechanical valve.

The patient had been discharged a month before after being hospitalized in the orthopaedic ward for a phlegmon of the second toe of the left foot, which was complicated with sepsis and subsequently required amputation. During her hospital stay, due to the sepsis and treatment with two loop diuretics (furosemide and torasemide), the patient developed severe hypocalcaemia with tetany, which was treated successfully with intravenous calcium gluconate, oral calcitriol, and switching to hydrochlorothiazide.

The patient was discharged on the following therapy, which she followed very carefully for a month before presenting to us: calcium carbonate $3,000 \mathrm{mg} /$ day, calcitriol $1 \mu \mathrm{g} /$ day for hypoparathyroidism, levothyroxine (125 $\mu \mathrm{g} / \mathrm{day}$ ) for hypothyroidism, Warfarin for anticoagulant prophylaxis, hydrochlorothiazide $(50 \mathrm{mg} /$ day) and potassium chloride (1,800 $\mathrm{mg} /$ day by mouth).

The patient also reported taking, on her own initiative and initially undeclared, two herbal supplements for constipation, namely anthranoid laxatives (total anthraquinones $105 \mathrm{mg} /$ day).

The patient reported that calcitriol $0.5 \mu \mathrm{g} /$ day had been sufficient to control her serum calcium since the thyroidectomy.

On examination, the patient was alert, confused and unsteady, with slurred speech. Pulse was 52 beats/minute and blood pressure $120 / 70$ $\mathrm{mmHg}$. Laboratory data on admission were as follows: serum calcium, $21.2 \mathrm{mg} / \mathrm{dl}$ (normal range: 8.4-10.2); ionized calcium, 9.52 mg/dl (4.61-5.17); serum phosphorus, $2.7 \mathrm{mg} / \mathrm{dl}$ (2.7-5.1); chloride, $88 \mathrm{mg} / \mathrm{dl}$ (98-110); potassium, $2.4 \mathrm{mmol} / \mathrm{l}$ (3.5-5.5); blood urea nitrogen, $56 \mathrm{mg} / \mathrm{dl}$ (5-25); creatinine, $4.36 \mathrm{mg} / \mathrm{dl}$ (0.5-1.4); serum bicarbonate, $38 \mathrm{mmol} / \mathrm{l}$ (24-31); arterial blood pH, 7.69; thyrotropin, $1.60 \mathrm{pU} / \mathrm{ml}$ (0.35-4.50); PTH, 4.8 pg/ml (6.0- 40.0); and 25(OH)D, 9.9 ng/ml (30-80). Chest x-ray was normal with no abnormalities. Ultrasound of the abdomen and head CT showed no relevant signs.

Initial treatment consisted of suspension of the patient's home therapy and urgent dialysis, followed by intravenous $\mathrm{NaCl} 0.9 \%$, loop diuretics and calcitonin. The treatment resulted in serum calcium reduction to $13.3 \mathrm{mg} / \mathrm{dl}$ and renal function improvement, although serum phosphorus dropped to $1.5 \mathrm{mg} / \mathrm{dl}$. Potassium levels were normalized with intravenous and oral potassium chloride. Over the following 3 days, the patient fully recovered her mental status, sensorium and speech. Serum calcium progressively dropped to $7.7 \mathrm{mg} / \mathrm{dl}$, serum phosphorus rose to $3.8 \mathrm{mg} / \mathrm{dl}$, serum potassium rose to $3.6 \mathrm{mmol} / \mathrm{l}$, and PTH levels increased to $16.6 \mathrm{pg} / \mathrm{ml}$. Consequently, the patient was restarted on intravenous calcium gluconate and calcitriol $0.25 \mu \mathrm{g} / \mathrm{day}$, while intravenous potassium chloride was suspended.

On the day of discharge, serum calcium was $7.5 \mathrm{mg} / \mathrm{dl}$, creatinine was $1.54 \mathrm{mg} / \mathrm{dl}$ and blood urea nitrogen was $22.1 \mathrm{mg} / \mathrm{dl}$. Since calcium supplementation was still required for treatment of the chronic hypoparathyroidism, the patient was discharged on a regimen of a nonalkali calcium supplement (oral calcium citrate $1,200 \mathrm{mg} / \mathrm{day}$ ) and calcitriol at her usual dose $(0.50 \mu \mathrm{g} / \mathrm{day})$, with recommendations to avoid any further alkaline calcium supplements and anthranoid laxative consumption. Other medicines for her comorbidities were prescribed. A 6-month follow-up was scheduled to monitor calcium levels and adjust therapy dosages.

\section{DISCUSSION}

This patient presented with the typical triad of milk-alkali syndrome, which consists of hypercalcaemia, metabolic alkalosis and renal failure. A 30-day history of high-dose calcium and absorbable alkali consumption was reported.

Low-normal phosphate levels fell further, which is common in the modern form of milk-alkali syndrome because of the chelating action of calcium carbonate, and low phosphorus intake. Potassium levels were low, which is consistent with diuretic use, metabolic alkalosis and chronic use of anthranoid laxatives.

The low PTH level, in line with her precedent residual baseline levels, was due to her post-surgical hypoparathyroidism. The increase in PTH levels concomitant with rebound hypocalcaemia after treatment with loop diuretics might also be suggestive of milk-alkali syndrome ${ }^{[2]}$. In 
this case, PTH levels during rebound hypocalcaemia were significantly higher than the patient's normal laboratory values.

Malignancy as a cause of the metabolic abnormality was excluded for the following reasons. The patient was 8 years free of cancer following surgery for papillary thyroid cancer, and biochemical parameters had been stable from thyroidectomy to her precedent hospitalization. Moreover, the metabolic abnormality had a relatively fast onset, and rapid normalization of the electrolyte values after suspension of calcium and alkali intake was observed.

Finally, tests for neoplastic markers were negative, and chest x-ray and abdomen ultrasound were negative for malignancy.

Low levels of 25(OH)D were present, excluding 25(OH)D intoxication; levels of $1,25(\mathrm{OH})_{2} \mathrm{D}$ were not measured. Since the patient had hypoparathyroidism, renal 1-hydroxylation of $25(\mathrm{OH}) \mathrm{D}$ into $1,25(\mathrm{OH})_{2} \mathrm{D}$ was reduced by low PTH levels, and also by chronic renal insufficiency. Therefore, the high-dose oral intake of calcitriol ( $1 \mu \mathrm{g} / \mathrm{day})$ for hypoparathyroidism and the recent episode of hypocalcaemia, in the presence of renal insufficiency, might have resulted in an elevated level of $1,25(\mathrm{OH})_{2} \mathrm{D}^{[3]}$. High $1,25(\mathrm{OH})_{2} \mathrm{D}$ levels could have caused an increase in the gastrointestinal fractional absorption of calcium carbonate, leading to milk-alkali syndrome. Moreover, the underlying chronic renal insufficiency might have inhibited calcium excretion by the kidney, thus contributing to the elevation of serum calcium levels. The onset of the acute renal insufficiency was due to the hypercalcaemia causing vasoconstriction of afferent arterioles and volume depletion. Alkalosis itself could have raised calcium levels by inhibition of calcium excretion (alkalosis stimulates TRPV5 Ca ${ }^{2+}$ channels on the apical membrane), initiating a spiral of increasing calcium levels.

Furthermore, the patient was under treatment with hydrochlorothiazide ${ }^{[4]}$, which has a specific action on the distal tubule, namely inhibition of sodium reabsorption and enhancement of calcium reabsorption, thus contributing to the elevation of serum calcium levels and fostering the increasing spiral.

In this case, a final precipitating factor leading to the onset of milk-alkali syndrome might have been the anthranoid laxatives. Chronic use of anthranoid laxatives can cause electrolyte imbalance and enhance the potassium depletion effect of diuretics ${ }^{[5,6]}$. Furthermore, some studies suggest that anthranoid laxatives can have nephrotoxic effects ${ }^{[7-11]}$, namely alteration of the calcium excretion mechanism. We hypothesize a possible role for these anthranoid derivatives through diminishing calcium excretion.

\section{CONCLUSIONS}

Our experience underlines the need for caution when treating patients with impaired calcium metabolism regulation, as well as the importance of a thorough investigation of pharmacological history to identify undeclared drug self-administration. This is important for the assessment of calcium and alkali intake and for recognition of the effect on calcium metabolism of prescribed and over-the-counter drugs, which might be trigger factors for milk-alkali syndrome. Further studies on the interaction of anthranoid laxatives with calcium metabolism are needed since these herbal products are widely used and often unreported, and their pharmacological activity is frequently not known to either patients or physicians.

\section{REFERENCES}

1. Beall DP, Henslee HB, Webb HR, Scofield RH. Milk-alkali syndrome: a historical review and description of the modern version of the syndrome. Am J Med Sci 2006;331:233242.

2. Picolos MK, Lavis VR, Orlander PR. Milk-alkali syndrome is a major cause of hypercalcaemia among non-end stage renal disease (non-ESRD) inpatients. Clin Endocrinol 2005;63:566-576.

3. Tal A, Powers K. Milk-alkali syndrome induced by 1,25(OH)2D in a patient with hypoparathyroidism. J Natl Med Assoc 1996;88:313.

4. Parvez B, Emuwa C, Faulkner ML, Murray JJ. Milk alkali and hydrochlorothiazide: a case report. Case Rep Med 2011;2011:729862.

5. Wang L, Pan X, Sweet DH. The anthraquinone drug rhein potently interferes with organic anion transporter-mediated renal elimination. Biochem Pharmacol 2013;86:991-996.

6. Ma L, Zhao L, Hu H, Qin Y, Bian Y, Jiang H, et al. Interaction of five anthraquinones from rhubarb with human organic anion transporter 1 (SLC22A6) and 3 (SLC22A8) and drug-drug interaction in rats. J Ethnopharmacol 2014;153:864-871.

7. Li FK, Lai CK, Poon WT, Chan AYW, Chan KW, Tse KC, et al. Aggravation of non-steroidal anti-inflammatory drug-induced hepatitis and acute renal failure by slimming drug containing anthraquinones. Nephrol Dial Transplant 2004;19:1916-1917.

8. Kwan TH, Tong MK, Leung KT, Lai CK, Poon WT, Chan YW, et al. Acute renal failure associated with prolonged intake of slimming pills containing anthraquinones. Hong Kong Med J 2006;12:394-397.

9. Foote J, Cohen B. Medicinal herb use and the renal patient. J Ren Nutr 1998:8:40-42

10. Jimenez RA, Larson EB. Case report. Tumoral calcinosis: an unusual complication of the laxative abuse syndrome. Am J Med Sci 1981;282:141-147.

11. Lim AK, Hooke DH, Kerr PG. Anorexia nervosa and senna misuse: nephrocalcinosis, digital clubbing and hypertrophic osteoarthropathy. Med J Aust 2008;188:121-122. 